\title{
T-Shirt with Propping Effect for Natural Ventilation: Design Development and Evaluation of its Functionality by Thermal Manikin in Standing and Walking Motions
}

\author{
Chupo $\mathrm{Ho}^{1 *}$, Jintu Fan², Edward Newton ${ }^{3}$ and Raymond $\mathrm{Au}^{4}$
}

${ }^{1}$ Institute of Textiles and Clothing, the Hong Kong Polytechnic University, Hung Hom, Kowloon, Hong Kong SAR, China ${ }^{2}$ College of Human Ecology, Cornell University, New York, USA

${ }^{3}$ Institute of Textiles and Clothing, The Hong Kong Polytechnic University, Hung Hom, Kowloon, Hong Kong SAR, China

${ }^{4}$ Hong Kong Design Institute Vocational Training Centre 3, King Ling Road, Tseung Kwan O, N.T., Hong Kong SAR, China

\begin{abstract}
To improve the natural ventilation of garments is often a crucial task in designing functional garments. Normally, the ventilation can be improved by using appropriate types of fabric, or applying functional design details such vented panels on certain parts of a garment. Apart from these two means, are there any other alternative ways that clothing designers can utilize? Designing is a means to solve problems. Through a patent search, it was found that some inventors have adopted different means of designing to improve natural ventilation. Putting mesh panels on the garments was the most common way to achieve such aim. This design method had been proven by scholarly researches on its contribution on heat and moisture transfer. In addition, some designers noted that the air gap between the garment and body could be a key to affect such natural ventilation. For example, Moretti proposed putting additional spacer objects under the shoulder areas to create a gap so as to improve the natural ventilation of the wearer. Although this new design was claimed to have contribution to enhance natural ventilation for the wearer, the testing results were not provided. In this study, T-shirt designed with larger air gaps on the shoulders was developed. In order to test the effectiveness of this design method on heat and moisture transfer, a series of testing were conducted by using a movable thermal manikin in a chamber with the control of temperature and relative humidity. In order to test the functionality of the chimney/pumping/ventilation effect, the testing was conducted under no wind and windy conditions with a thermal manikin in a standing position, and under a simulated "walking" motion (walking speed of $1.24 \mathrm{~km} / \mathrm{h}$ ). The test results showed that the T-shirt with a larger air gap on the shoulders can significantly improve moisture vapor resistance during windy conditions.
\end{abstract}

Keywords: Functional clothing; T-shirt; Design; Natural ventilation; Pumping effect

\section{Introduction}

Clothing is not only a commodity that meets our basic needs or an item of aesthetic appreciation, but also a portable environment that helps us to face different external conditions every day. In order to do so, a true functional garment is one that can protect our body from acute changes in the environment. However, the body will generate heat, which will eventually result in sweating. If heat and sweat cannot be efficiently transmitted out through our clothing and released into the external environment, they not only cause heat stress and affect our performance, but in extreme cases, would even lead to death. Since clothing has been found to be an obstacle that defers a certain amount heat and moisture transfer [1-5], the maintaining of heat and moisture transfer to a consistent level is one of the key elements that clothing designers have to bear in mind. Therefore, fabrics that have moisture management can be a simple way to solve the problem. Moisture management materials are fabrics that can absorb sweat and vaporize moisture away from the skin surface from one side to the other side for faster evaporation. Many types of sports clothing that use these types of fabrics have the ability to maintain dryness for the wearers. However, moisture management fabrics are not able to enhance natural ventilation for the wearer. The attaching of devices in the clothing system such as cold pads or fans can actively increase ventilation; however, this is not feasible for daily wear due to the extra weight and bulkiness. Thus, natural ventilation can be increased through clothing design only, which will be more simple and direct. In this regard, the placement of vented panels, such as openings or through the use of mesh fabrics to allow for better natural ventilation to the wearer, has become very common in sports clothing designs. The advantages and the effect of similar garment types have been reported by many researchers [6-8]. However, simply placing vented panels onto clothing has been carried out by many designers/brands for many years, and it seems that there are a lack of breakthroughs on improving natural ventilation by using other design methods. Apart from placing vented panels onto garments, are there any other options for designers in developing functional garments to improve natural ventilation? The objective of this paper is to explore an alternative design method which may have potential in improving natural ventilation for wearers. According to this design concept, a set of garment prototypes will be created and tested by objective measurements. The data will be analyzed to determine the effectiveness of the new design on improving natural ventilation. Finally, a recommendation will be provided for further design development.

\section{Pumping Effect and Clothing Design}

For a clothed person, there will be more or less air entrapped

${ }^{*}$ Corresponding author: Chupo $\mathrm{HO}$, Institute of Textiles and Clothing, the Hong Kong Polytechnic University, Hung Hom, Kowloon, Hong Kong SAR, China, Tel: 852-27731432; E-mail: tccpho@polyu.edu.hk

Received July 17, 2015; Accepted July 27, 2015; Published August 17, 2015

Citation: Ho C, Fan J, Newton E, Au R (2015) T-Shirt with Propping Effect for Natural Ventilation: Design Development and Evaluation of its Functionality by Thermal Manikin in Standing and Walking Motions. J Textile Sci Eng 5: 210. doi:10.4172/2165-8064.1000210

Copyright: (C) $2015 \mathrm{Ho} \mathrm{C}$, et al. This is an open-access article distributed under the terms of the Creative Commons Attribution License, which permits unrestricted use, distribution, and reproduction in any medium, provided the original author and source are credited. 
between the clothing layers, or between the skin and fabric layer if he is wearing a garment with only a single layer fabric. As the thermal conductivity of still air is low, solutions should be sought for improving exchange between the inner warmer microclimate and the outside environment, and this is known as air ventilation. One of the most common ways to do this is through open apertures in clothes in order to increase the exchange between the air inside the clothing and the ambient air. Moreover this ventilation will be further increased by the pumping effect of body movement. Clothing with openings involves "indirect" and "direct" ventilation. "Indirect ventilation" refers to the exchange of the garment microclimate through the materials itself; while "direct ventilation" means that the microclimate between garment and ambient air is formed by openings in the garment [9]. Direct ventilation, known as forced ventilation, can carry away warm air from the skin and fabric layer and also assist in evaporating sweat and dissipating warm vapor. When people move, the air of the garment microclimate can be influenced by the ambient environment through the openings of the garment or pores in the fabric [2,10-13]. The air space between the skin and the inner fabric layer changes over time, depending on the level of activity and movement. During body movements, air must go in and out through openings (such as the collar and cuffs) as the fabric moves outward and inward towards the skin surface, thus leading to ventilation. This ventilation of the microclimate of the clothing is called the "pumping effect" [14].

When a garment is properly worn, it tends to hang on the shoulders and thus the fabric touches the skin surface due to natural gravity. As warm air rises, similar to a chimney effect, one may feel warm on the upper chest and upper back due to the trapping of warm air in these areas. To address this issue, two questions can be raised. If there are vented panels on both shoulder areas, will the natural ventilation improve? Second, if there are vented panels on top of both of the shoulder areas, when the wearer swings his or her arms (viz. walking), will heat and moisture be released through the vented panels more significantly through the pumping effect? These two questions will be the key considerations that are kept in mind when exploring the different methods for clothing design in this research work.

Designing is a means to solve problems. Through a patent search, it was found that some inventors have adopted different means of designing to improve natural ventilation. According to Peteu and Helvenston Gray [15], patents are one of the best ways to explore how various products are designed to solve particular problems. Many studies have used patents as an important source of information on clothing development [15-17]. This research uses a patent search to review some of the design examples with special design features that improve natural ventilation. Although sometimes the patents showed descriptions and sketches by the applicants, the test results of the invention are not provided and the data are not shown. Thus, it is difficult to determine the functionality of the final product from the patents themselves [15]. However, a patent search is still useful because we can see how the potential proposal/design may solve specific problems. In terms of designs that will improve natural ventilation, the following are some examples taken from the patent search.

Putting mesh on the garments is not a new technique for improving ventilation. In 1944, Zelano [18] used lace fabrics and put them into the garment for ventilation purpose. In his design, he put lace as stripe-like openings on various positions of the garment such as the front, back panel, sleeves and trousers. For the suit, the lace was not only put on the shell fabric but also on the lining layer. Lace, in this case, could release the body heat and moisture vapor away because of the porous structure of this fabrication.
Bengtsson et al. [19] invented a garment for vigorous physical activity in warm environments. The inventors placed cords underneath a garment to create many piles of vertical air channels. Warm body air and moisture vapor could be released through the gaps between each cord channel.

Gioello [20] developed a ribbed ventilating undergarment which is worn beneath a non-porous outer garment. In this design, she used a series of parallel raised ribs or cords to form air channels. The channels would come into contact with the base of the outer garment so that a wider air gap between the channels can be formed. By creating a wider gap between the undergarment and the outer garment, the inventor claimed that body heat and moisture from the undergarment could be transferred and released through this air gap.

Lemoine [21] invented a garment for beekeepers. By placing a layer of polyurethane open cell foam that was approximately $0.4-0.6 \mathrm{~cm}$ in thickness underneath net fabric, bees cannot penetrate the material and sting the skin surface. At the same time, Lemoine claimed that this invention could allow ventilation between the skin of the wearer and the outside air.

Moretti [1] made use of a similar concept and invented a garment in which spacer objects are placed under the shoulder areas to create a gap. With the aid of vented panels on the shoulders, the accumulated warm air from the shoulders could be released to the outside, by assuming that warm air tends to rise in the space between the garment layer and body skin surface. He also indicated that solely creating an air gap between the garment and skin surface might be inadequate. It could be possible that the inside air would not be released from the shoulder areas, so that the air gap area increases in heat and moisture vapor resistance, and the wearer would experience an increase in discomfort. Thus he created openings on the shoulder parts of the garment. Warm air could dissipate, much like a chimney effect. The allowance of space between a garment and the skin could create air circulation around the body. However, it should be mentioned that if such air is damp, warm air may accumulate and thus create even more thermal insulation for the body. Thus, Moretti [1] pointed out the importance of air movement between a garment and the skin. This design approach seems to be a potential design that use vented panels to improve the natural ventilation for the wearer. More important, this design is easy to make and more light weight, as only two extra objects are needed on shoulders.

\section{Design Development of T-Shirts}

\section{Design of objects that prop garments}

According to the designs searched from the patent, the designers got the similar idea of the garment. They pointed out that keeping distance between fabric layer and skin surface could improve the air circulation, as the propping up effect could reduce the area that the fabric layer stuck to the skin directly. With reference to the design per Moretti, spacer shoulder pads were placed underneath the shoulder areas to refrain the garment from contact with the body. To enhance the pumping effect, piles of spacer material were cut to construct "shoulder pads" in the first trial. The shoulder pads could be used for "propping up" the garment, but if excessive piles of spacer material were stacked together (Figure 1), it was considered to be possibly too heavy for the wearer. Furthermore, the thickness of the material could increase thermal insulation by reducing air flow, although the spacer material is fabricated with porous material. Therefore, this method had to be modified. 
To cope with the problem of the lack of air flow within spacer objects, "U-shaped" members (Figures $2 \mathrm{~A}$ and $2 \mathrm{~B}$ ) were chosen to address this issue. In the construction of the $U$-shaped members, wider space was created between the layers of the spacer materials so that theoretically, this would discourage still air from accumulating, thus increase the flow of air penetration, which would contribute to the transfer of heat and moisture vapor away from the skin. However, there were two main problems that were found once this design was created. The first problem was the collapse of the U-shaped members (Figure 2C). Although the spacer material used for the experiment was ideal in its stiffness, it could not hold the shape of the U-waves once the T-shirt was placed onto the body without distortion. This suggests that when the U-shape wave design was placed onto the body, gravity and the weight of the T-shirt pressed downwards onto the U-shape waves. This resulted in reduced distance between the garment and the skin surface, i.e., reduced space and air circulation. Thus, the construction had to be further developed to minimize the amount of collapsing. The second problem was the bending of the spacer material, i.e. its tendency to be flattened (Figure 2D), thus making it difficult to control the U-shaped waves of the spacer material.

In order to hold the U-shape of the waves without distortion or bending, loops were continuously formed so as to reduce the space between each individual wave (Figure 3 ). To solve the bending problem, a piece of flat spacer material was placed between the loops and T-shirt fabric to provide a stronger base. In addition, horizontal stitches were used to gather the loops together, while other vertical
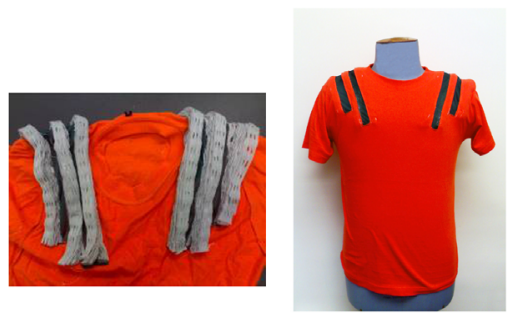

Figure 1: Spacer shoulder pad. (Left: inner construction; Right: T-shirt).

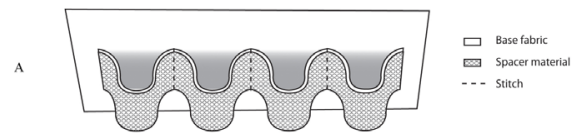

B
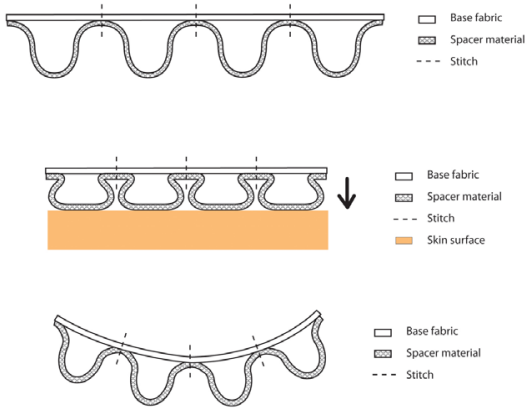

ㅁ. Base fabric

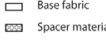

Figure 2: The design of "wave" construction of the spacer piles.
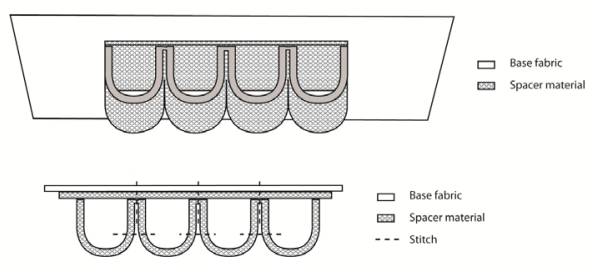

Figure 3: Design of the continuous loops of spacer material.

stitches were used to attach the loops and T-shirt fabric together. These two types of stitches eliminated the recovery ability of the spacer loops, so that the problem of bending was solved. Additionally, the sides of each U-shaped wave were stitch gathered together to reinforce them so that they were strong enough to support the weight of the garment, and a desirable distance could be maintained between the shell fabric and the surface of the body skin with minimum distortion.

\section{T-shirt designs}

The placement of mesh panels has been proven to have different effects on natural ventilation of garments. In this study, placement of mesh panels was carried out to determine its relationship with propping up effect on the improvement of pumping effect. The T-shirt designs were categorized into two groups: those without spacer loops (Group 1) and with spacer loops (Group 2) underneath the shoulders. Each group had five T-shirt styles, with different placements of mesh panels as previous studies have indicated that the positioning of vented panels could affect the natural ventilation of garments. The aim was to test the performance of the T-shirts with the placement of vented panels, whether this can work with a prop-up effect. The prototypes were made into the following five styles: NM (no meshes on the T-shirt), MS (meshes on the shoulders), MSC (meshes on the shoulders and chest area), MSS (meshes on the shoulders and two sides in the front) and $\mathrm{MO}$ (meshes on shoulders, chest area, and two sides in the front). Figure 4 shows all of the T-shirt styles, and the vented panels are presented as shaded areas. Each T-shirt was constructed with a zipper at the back for ease of placing the T-shirt onto the thermal manikin. Figure 5a shows one of the prototypes (Group 2-MO) and its inner construction (Figure 5b). NM of Group 1 was a basic T-shirt, and used as the control piece in the testing for comparison of the performance of heat and moisture transfer with the other T-shirts. For the main body of the T-shirts, a basic fabric typically available in the market was used, which was a $100 \%$ cotton fine gauge jersey with a weight of $200 \mathrm{~g} / \mathrm{m}^{2}$. The mesh fabric was also common in the market, $100 \%$ polyester with a weight of $66.3 \mathrm{~g} / \mathrm{m}^{2}$.

\section{Measurement method}

Wearer trial by subjects is not considered in this stage of product development. Since the fabric quality of the spacer loops are still not the best up to this stage, the results of the subjective measurement may not be reliable because more or less the subjects may have bias due to the quality of this spacer material. In order to obtain a more objective measurement to evaluate the design, a walkable thermal manikin may be the most ideal method. These thermal manikins are widely used to evaluate the thermal comfort of specific types of functional clothing, such as flight suits [22] and body protection during horse-riding [23]. In the same environmental setting, thermal manikins measure heat loss in a relevant, reliable and accurate way. In order to test the functionality of the chimney/pumping/ventilation effect, the testing was conducted 

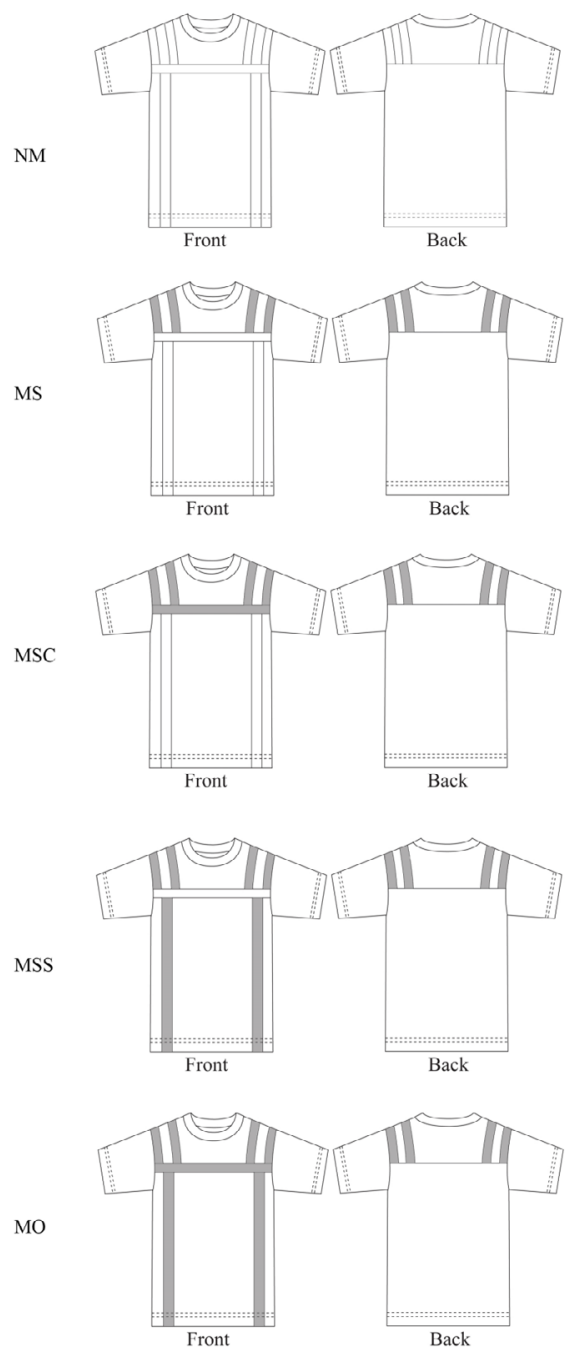

Figure 4: T-shirts and codes. The shaded areas represent the mesh panels of the T-shirts.

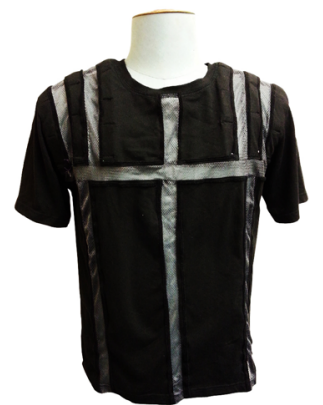

Figure 5a: The front view of T-shirt MO

under no wind and windy conditions with a thermal manikin in a standing position, and under a simulated "walking" motion (walking speed of $1.24 \mathrm{~km} / \mathrm{h}$ ). In the walking mode, the arms and legs of the manikin were swinging like the walking posture of a real human. The experiment was conducted in a climatic chamber of $20.0 \pm 0.5^{\circ} \mathrm{C}$ and

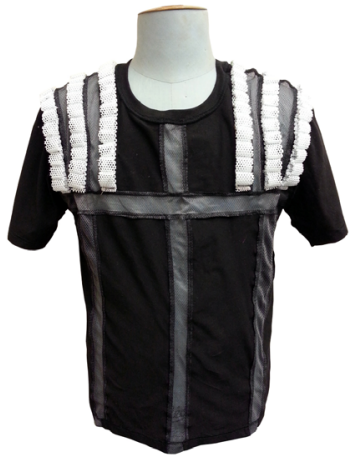

Figure 5b: The front view T-shirt MO with inside-out view.

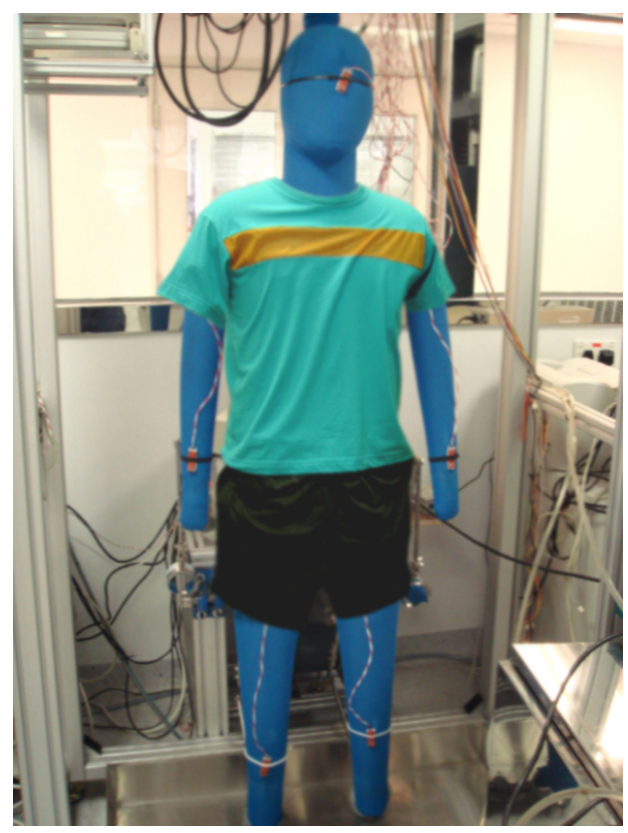

Figure 6: The thermal manikin.

$65.0 \pm 2 \%$ relative humidity $(\mathrm{RH})$ with an air velocity of $0.5 \pm 0.3 \mathrm{~m} / \mathrm{s}$ (no wind condition) and $2.0 \pm 0.3 \mathrm{~m} / \mathrm{s}$ (windy condition). The core temperature of the manikin was set at $37^{\circ} \mathrm{C}$. For all of the tests with the various T-shirt prototypes, the same pair of short trousers (made of $100 \%$ cotton) was placed on the manikin. Each T-shirt was tested three times, from which the mean value was taken. In order to avoid the effects of dirt and grime, which would possibly affect the testing results, the T-shirts were washed once by the laundry machine before undergoing testing. Clothing thermal insulation $\left(\mathrm{R}_{t}\right)$ and moisture vapor resistance $\left(R_{e t}\right)$ are the two most important parameters for thermal comfort. Therefore, a sweating fabric manikin (Figure 6) was used, which allowed these two parameters to be effectively determined [24]. T-test will be used to evaluate the performance of the reduction of thermal insulation and moisture vapor resistance.

According to the specifications of the sweating thermal manikin, the total thermal insulation, including the insulation of the clothing and surface air layer, is calculated as:

$$
R_{t}=\frac{A_{s}\left(T_{s}-T_{a}\right)}{H_{s}+H_{p}-H_{e}},
$$


Citation: Ho C, Fan J, Newton E, Au R (2015) T-Shirt with Propping Effect for Natural Ventilation: Design Development and Evaluation of its Functionality by Thermal Manikin in Standing and Walking Motions. J Textile Sci Eng 5: 210. doi:10.4172/2165-8064.1000210

Page 5 of 7

where $A_{s}$ is the total surface area of the manikin $\left(A_{s}=1.79 \mathrm{~m}^{2}\right), T_{s}$ is the mean skin temperature, $T_{a}$ is the mean temperature of the environment, $H_{s}$ is the heat supplied to the manikin or the heat generated by the heaters, $H_{p}$ is the heat generated by the pump, and $H_{e}$ is the evaporative heat loss from water evaporation. The evaporative heat loss can be calculated by using

$$
H_{e}=\lambda Q
$$

where $\lambda$ is the heat of the evaporation of water at the skin temperature, and $Q$ is the perspiration rate or water loss per unit time, which can be measured by measuring the water supply.

The total moisture vapor resistance, including that of the clothing and the surface air layer, can be calculated by using

$$
R_{e t}=\frac{A_{s}\left(P_{s}^{*}-R H_{a} P_{a}^{*}\right)}{H_{e}}-R_{e s}
$$

where $P_{s}^{*}$ is the saturated water vapor pressure at the skin temperature, which is the water vapor pressure of the water film on the skin. $R H_{a}$ is the relative humidity of the surrounding environment as a fraction, $P^{*}$ is the saturated water vapor pressure in the surrounding environment, and $R_{e s}$ is the moisture vapor resistance of the skin.

\section{Results and Discussion}

The results from all the T-shirts are listed in Table 1 for both the no wind and windy conditions, respectively. The coefficients of variation for the repeated tests are less than $5 \%$. T-shirts with lower $R_{t}$ and $R_{e t}$ values are preferred because they indicate that the design has a greater ability to release body heat and moisture vapor out into the ambient environment.

\section{Thermal insulation under no wind condition}

Table 2 shows the percentage change for each garment under the no wind condition. As mentioned, the basic T-shirt (NM) of Group 1 was the control piece for comparison purposes. From the testing results, it can be seen that the new designs cannot significantly reduce the thermal insulation of the garment under a no wind condition. In a standing posture, MSC ( $\mathrm{t}(4)=1.201, \mathrm{p}=0.296)$, MSS ( $\mathrm{t}(4)=1.331$, $\mathrm{p}=0.254)$ and $\mathrm{MO}(\mathrm{t}(4)=1.549, \mathrm{p}=0.196)$ of Group 2 (with spacer loops) reduce only $4 \%$ of the thermal insulation compared to the control piece. In a walking posture, MSS and MO of Group 2 achieve the best performance in reducing thermal insulation, although the percentage of change is only $2.59 \%(\mathrm{t}(4)=1.441, \mathrm{p}=0.223)$ and $3.45 \%(\mathrm{t}(4)=1.922$, $\mathrm{p}=0.127$ ), respectively. The findings indicate that placing spacer loops in a continuous manner underneath the shoulders cannot significantly reduce the thermal insulation, irrespective of standing or walking when there is no wind.

\section{Thermal insulation under windy condition}

Table 3 shows the percentage change for each garment compared with the control piece (NM of Group 1) during standing and walking under a windy condition. From the results, it appears that generally T-shirts in Group 2 perform better with lower thermal insulation compared to those in Group 1 under a windy condition. In a standing position, MSC ( $\mathrm{t}(4)=80573, \mathrm{p}=0.001)$, MSS and MO of Group 2 show more than a $10 \%$ reduction in thermal insulation compared to the control piece, although when they are compared to the same styles in Group 1, the difference between the two is minimal (approximately $1.5 \%$ to $3 \%)$.

In the walking mode, the T-shirts in Group 2 are not able to demonstrate a significant reduction in thermal insulation in comparison with those in Group 1. MSC, MSS and MO of Group 2 reduce thermal insulation by $6.35 \%(\mathrm{t}(4)=4.899, \mathrm{p}=0.008), 7.94 \%(\mathrm{t}$ $(4)=6.124, p=0.004)$ and $7.94 \%(t(4)=6.124, p=0.004)$, respectively, relative to the control piece. However the same designs in Group 1 also produce a $6.35 \%$ reduction in thermal insulation compared with the control piece. Thus the difference is very minimal.

The results for thermal insulation in the two positions during no wind and windy conditions show that although the new designs of

\begin{tabular}{|c|c|c|c|c|c|c|c|c|c|c|}
\hline & & & \multicolumn{2}{|c|}{ Standing (no wind) } & \multicolumn{2}{|c|}{ Walking (no wind) } & \multicolumn{2}{|c|}{ Standing (windy) } & \multicolumn{2}{|c|}{ walking (windy) } \\
\hline & & & Mean & S.D & Mean & S.D & Mean & S.D & Mean & S.D \\
\hline \multirow[t]{10}{*}{ Group 1} & \multirow[t]{2}{*}{ NM } & $\mathrm{R}_{\mathrm{t}}$ & 0.126 & 0.006 & 0.116 & 0.003 & 0.067 & 0.001 & 0.063 & 0.001 \\
\hline & & $\mathrm{R}_{\mathrm{et}}$ & 20.85 & 0.45 & 18.51 & 0.3 & 7.52 & 0.23 & 7.57 & 0.23 \\
\hline & \multirow[t]{2}{*}{ MS } & $\mathrm{R}_{\mathrm{t}}$ & 0.122 & 0.005 & 0.113 & 0.004 & 0.064 & 0.001 & 0.061 & 0.003 \\
\hline & & $\mathrm{R}_{\mathrm{et}}$ & 18.82 & 0.65 & 17.643 & 0.37 & 7.35 & 0.13 & 6.861 & 0.33 \\
\hline & \multirow[t]{2}{*}{ MSC } & $\mathrm{R}_{\mathrm{t}}$ & 0.121 & 0.005 & 0.115 & 0.003 & 0.062 & 0.01 & 0.059 & 0.002 \\
\hline & & $\mathrm{R}_{\mathrm{et}}$ & 18.72 & 0.55 & 17.301 & 0.45 & 6.52 & 0.2 & 6.902 & 0.28 \\
\hline & \multirow[t]{2}{*}{ MSS } & $\mathrm{R}_{\mathrm{t}}$ & 0.119 & 0.005 & 0.113 & 0.004 & 0.062 & 0.001 & 0.059 & 0.001 \\
\hline & & $\mathrm{R}_{\mathrm{et}}$ & 18.85 & 0.47 & 17.5 & 0.47 & 6.48 & 0.13 & 6.646 & 0.23 \\
\hline & \multirow[t]{2}{*}{ MO } & $\mathrm{R}_{\mathrm{t}}$ & 0.119 & 0.005 & 0.114 & 0.002 & 0.061 & 0.001 & 0.059 & 0.001 \\
\hline & & $\mathrm{R}_{\mathrm{et}}$ & 18.77 & 0.44 & 17.439 & 0.13 & 6.4 & 0.24 & 6.309 & 0.14 \\
\hline \multirow[t]{10}{*}{ Group 2} & \multirow[t]{2}{*}{ NM } & $\mathrm{R}_{\mathrm{t}}$ & 0.126 & 0.005 & 0.116 & 0.003 & 0.063 & 0.002 & 0.063 & 0.002 \\
\hline & & $\mathrm{R}_{\mathrm{et}}$ & 20.42 & 0.5 & 18.354 & 0.37 & 7.52 & 0.1 & 7.115 & 0.05 \\
\hline & \multirow[t]{2}{*}{ MS } & $\mathrm{R}_{\mathrm{t}}$ & 0.123 & 0.004 & 0.116 & 0.003 & 0.062 & 0.001 & 0.062 & 0.001 \\
\hline & & $\mathrm{R}_{\mathrm{et}}$ & 18.02 & 0.5 & 17.632 & 0.55 & 7.36 & 0.15 & 6.8 & 0.07 \\
\hline & \multirow[t]{2}{*}{ MSC } & $\mathrm{R}_{\mathrm{t}}$ & 0.121 & 0.004 & 0.114 & 0.004 & 0.06 & 0.001 & 0.059 & 0.001 \\
\hline & & $R_{e t}$ & 18.21 & 0.29 & 17.341 & 0.21 & 6.42 & 0.22 & 6.199 & 0.25 \\
\hline & \multirow[t]{2}{*}{ MSS } & $\mathrm{R}_{\mathrm{t}}$ & 0.12 & 0.005 & 0.113 & 0.002 & 0.06 & 0.001 & 0.058 & 0.001 \\
\hline & & $R_{\text {et }}$ & 18.51 & 0.46 & 17.284 & 0.53 & 6.32 & 0.2 & 6.152 & 0.22 \\
\hline & \multirow[t]{2}{*}{$\mathrm{MO}$} & $\mathrm{R}_{\mathrm{t}}$ & 0.12 & 0.003 & 0.112 & 0.002 & 0.06 & 0.001 & 0.058 & 0.001 \\
\hline & & $\mathrm{R}_{\mathrm{et}}$ & 18.17 & 0.54 & 17.282 & 0.42 & 5.9 & 0.14 & 5.845 & 0.17 \\
\hline
\end{tabular}
Group 2 could reduce a certain amount of thermal insulation compared

Table 1: $R_{t}$ and $R_{\text {et }}$ values of standing and walking modes in both no wind and windy conditions. 
Citation: Ho C, Fan J, Newton E, Au R (2015) T-Shirt with Propping Effect for Natural Ventilation: Design Development and Evaluation of its Functionality by Thermal Manikin in Standing and Walking Motions. J Textile Sci Eng 5: 210. doi:10.4172/2165-8064.1000210

Page 6 of 7

\begin{tabular}{|c|c|c|c|c|c|c|c|c|c|c|}
\hline \multicolumn{6}{|c|}{ Group 1} & \multicolumn{5}{|c|}{ Group 2} \\
\hline & NM & MS & MSC & MSS & MO & NM & MS & MSC & MSS & MO \\
\hline Standing $R_{t}(\%)$ & $0 \%$ & $-3.17 \%$ & $-3.97 \%$ & $-5.56 \%$ & $-4.76 \%$ & $0 \%$ & $-2.38 \%$ & $-3.97 \%$ & $-4.76 \%$ & $-4.76 \%$ \\
\hline Walking $R_{t}(\%)$ & $0 \%$ & $-2.59 \%$ & $-0.86 \%$ & $-2.59 \%$ & $-1.72 \%$ & $0 \%$ & $0 \%$ & $-1.72 \%$ & $-2.59 \%$ & $-3.45 \%$ \\
\hline
\end{tabular}

Table 2: Percentage change in total thermal insulation for all T-shirts for standing and walking postures during no wind condition.

\begin{tabular}{|l|c|c|c|c|c|c|c|c|c|c|}
\hline \multicolumn{9}{|c|}{ Group 1 } & \multicolumn{3}{c|}{ Group 2 } \\
\hline & NM & MS & MSC & MSS & MO & NM & MS & MSC & MSS & MO \\
\hline Standing $\mathrm{R}_{\mathrm{t}}(\%)$ & $0 \%$ & $-4.48 \%$ & $-7.46 \%$ & $-7.46 \%$ & $-8.96 \%$ & $-5.97 \%$ & $-7.46 \%$ & $-10.45 \%$ & $-10.45 \%$ & $-10.45 \%$ \\
\hline Walking $\mathrm{R}_{\mathrm{t}}(\%)$ & $0 \%$ & $-3.17 \%$ & $-6.35 \%$ & $-6.35 \%$ & $-6.35 \%$ & $0 \%$ & $-1.59 \%$ & $-6.35 \%$ & $-7.94 \%$ & $-7.94 \%$ \\
\hline
\end{tabular}

Table 3: Percentage change in total thermal insulation for all T-shirts for standing and walking postures under windy condition.

\begin{tabular}{|c|c|c|c|c|c|c|c|c|c|c|}
\hline \multicolumn{6}{|c|}{ Group 1} & \multicolumn{5}{|c|}{ Group 2} \\
\hline & NM & MS & MSC & MSS & MO & NM & MS & MSC & MSS & MO \\
\hline Standing $R_{t}(\%)$ & $0 \%$ & $-9.74 \%$ & $-10.22 \%$ & $-9.59 \%$ & $-9.98 \%$ & $-2.06 \%$ & $-13.57 \%$ & $-12.66 \%$ & $-11.22 \%$ & $-12.85 \%$ \\
\hline Walking $R_{t}(\%)$ & $0 \%$ & $-4.68 \%$ & $-6.53 \%$ & $-5.46 \%$ & $-5.79 \%$ & $-0.84 \%$ & $-4.74 \%$ & $-6.32 \%$ & $-6.62 \%$ & $-6.63 \%$ \\
\hline
\end{tabular}

Table 4: Percentage change of moisture vapor resistance for all T-shirts for standing and walking postures under no wind condition.

\begin{tabular}{|l|c|c|c|c|c|c|c|c|c|c|}
\hline \multicolumn{9}{|c|}{ Group 1 } & \multicolumn{3}{c|}{ Group 2 } \\
\hline & NM & MS & MSC & MSS & MO & NM & MS & MSC & MSS & MO \\
\hline Standing $\mathrm{R}_{\mathrm{t}}(\%)$ & $0 \%$ & $-2.26 \%$ & $-13.30 \%$ & $-13.83 \%$ & $-14.89 \%$ & $0 \%$ & $-2.13 \%$ & $-14.63 \%$ & $-15.96 \%$ & $-21.54 \%$ \\
\hline Walking $\mathrm{R}_{\mathrm{t}}(\%)$ & $0 \%$ & $-9.37 \%$ & $-8.82 \%$ & $-12.21 \%$ & $-16.66 \%$ & $-6.01 \%$ & $-10.17 \%$ & $-18.11 \%$ & $-18.73 \%$ & $-22.79 \%$ \\
\hline
\end{tabular}

Table 5: Percentage change of moisture vapor resistance for all T-shirts for standing and walking postures under windy condition.

to the control, the performance is not that remarkable if compared with the same designs in Group 1 (viz. a propping effect). Hence, the new design in Group 2 does not attain a large amount of reduction in thermal insulation in comparison with that of Group 1. For the tests, each T-shirt utilized was made of only a single layer of fabric, so its original thermal insulation value was already quite low. Perhaps this is the primary reason that the designs that use propping may not be able to obtain an even lower value. Hence, performance in moisture vapor resistance could instead be the key factor for determining the degree of natural ventilation.

\section{Moisture vapor resistance under no wind condition}

Table 4 shows the percentage change of each garment compared with the control piece (NM of Group 1) under a no wind condition. Under a no wind condition and standing posture, the designs of Group 2 including MS ( $\mathrm{t}(4)=7.287, \mathrm{p}=0.002)$, MSC $(\mathrm{t}(4)=8.541, \mathrm{p}=0.001)$, MSS ( $\mathrm{t}(4)=6.298, \mathrm{p}=0.003)$ and MO ( $(4)=6.604, \mathrm{p}=0.003)$ show significantly reduced moisture vapor resistance relative to the control by about $11 \%$ to $13 \%$. In comparison, the designs of Group 1 reduce moisture vapor resistance by nearly $10 \%$ compared to the control piece. This means that the open mesh panels alone on the T-shirt already reduce a certain amount of moisture vapor resistance, and the placing of additional spacer loops underneath the shoulders in Group $2 \mathrm{~T}$-shirts is only a minor contribution (the difference is approximately $1 \%$ to $3 \%$ ) when compared with the designs of Group 1. In the walking posture, all $\mathrm{T}$-shirts recorded lower $\mathrm{R}_{\mathrm{et}}$ than the control piece, and thus the designs of Group 2 do not have a significant advantage over the designs of Group 1.

\section{Moisture vapor resistance under windy condition}

The percentage change of the $\mathrm{R}_{\mathrm{et}}$ values is listed in Table 5. For standing postures, MSC, MSS and MO of Groups 1 and 2 show over $10 \%$ lower moisture vapor resistance than the control piece. Among these, $\mathrm{MO}$ of Group 2 has the best performance with a reduction in the $\mathrm{R}_{\mathrm{et}}$ by $21.54 \%(\mathrm{t}(4)=5.836, \mathrm{p}=0.004)$ relative to the control piece. The data also show that for a standing posture under windy conditions, open meshes on the shoulders are not as effective in releasing moisture vapor, irrespective of the presence of spacer loops. This suggests that the convection or chimney effect is not as effective for this design, unlike other designs with mesh panels placed across the chest, or two front vertical side panels near the side seams, even when both panels were kept open. It can be seen that when the meshes were placed only on the shoulders, approximately $2 \%$ lower $\mathrm{R}_{\mathrm{et}}$ was recorded as opposed to the control piece ( $\mathrm{t}(4)=1.009, \mathrm{p}=0.37$ ). Once the mesh panels of other body parts were opened, the percentage of reduction increased from approximately $2 \%$ to $13-14 \%$, and the differences were significant (MSC: $\mathrm{t}(4)=5.986, \mathrm{p}=0.004$; MSS: $\mathrm{t}(4)=6.818, \mathrm{p}=0.002$; MO: $\mathrm{t}(4)=5.836, \mathrm{p}=0.004)$. This indicates that vented designs placed solely on the shoulders cannot achieve a chimney effect, although moisture vapor would still be released from the porous fabric. However, if mesh panels were placed on other body parts at the same time, the ventilation effect would be more relevant. This result showed that dry air could enter the T-shirt through these mesh panels, and carry away the moisture vapor by natural convection.

In a walking posture, again, $\mathrm{MO}$ of Group 2 shows the lowest $\mathrm{R}$ value compared to the others, which is $22.79 \%(\mathrm{t}(4)=10.447, \mathrm{p}=0.000)$ lower than the control piece, and 6.13\% ( $\mathrm{t}(4)=3.649, \mathrm{p}=0.022)$ lower than MO in Group $1(-16.66 \%)$. MSC and MSS of Group 2 show lower values for $\mathrm{R}_{\mathrm{et}}$ that is, $18.11 \%(\mathrm{t}(4)=6.99, \mathrm{p}=0.002)$ and $18.73 \%(\mathrm{t}$ $(4)=7.717, p=0.002)$, respectively. Body motion thus contributed to a further reduction in moisture vapor resistance. The test result showed that the new design could have better performance to reduce moisture vapor resistance, when the mesh panels on other body parts were placed, and the wearer was moving arms in a windy condition.

\section{Conclusions}

The experiment in this research work shows that $\mathrm{T}$-shirts with newly 
Citation: Ho C, Fan J, Newton E, Au R (2015) T-Shirt with Propping Effect for Natural Ventilation: Design Development and Evaluation of its Functionality by Thermal Manikin in Standing and Walking Motions. J Textile Sci Eng 5: 210. doi:10.4172/2165-8064.1000210

designed spacer objects could reduce moisture vapor resistance relative to a normal T-shirt in certain testing conditions. T-shirt is a simple garment not intended for thermal protection, its thermal insulation is less important than its moisture vapor resistance with respect to thermal comfort. Therefore, the sole application of meshes or other vented panels on the shoulders is not the best solution for reducing the total thermal insulation and moisture vapor resistance, especially when the manikin was in a no wind condition. Perhaps the air gap between the shoulders and fabric layer is too limited in the prototypes, or the choice of spacer material defer the heat and moisture transfer from the body, the "pumping effect" of the thermal manikin could not actively improve the natural ventilation in no wind condition. However, the test results provided foundation for product development in the future. The placement of mesh panels on the body is vital. Together with the propping up and create opening on the shoulder areas, the garment may have different effects on the improvement on moisture vapor transfer. If this design concept can be applied on other functional wear, thus the user may be able to adjust the level of thermal comfort according to different environmental conditions, especially the change of relative humidity. In the future, the T-shirts with propping up effect should be evaluated by wearer trial. Apart from the analysis of the new design concept under real situation of doing exercise, it is also vital to investigate to what extent the presence of the spacer material may cause discomfort to the wearer.

\section{References}

1. Moretti MP (2002) Ventilaed item of clothing, US Patent 6442760B2.

2. Haghi A (2004) Moisture permeation of clothing: A factor governing thermal equilibrium and comfort. J Thermal Analysis and Calorimetry 76: 1035-1055.

3. Levine L, Sawka MN, Gonzalez RR (1998) Evaluation of clothing systems to determine heat strain. American Industrial Hygiene Association J 59: 557-562.

4. Nielsen R, Gavhed DC, Nilsson H (1989) Thermal function of a clothing ensemble during work: Dependence on inner clothing layer fit. Ergonomics 32:1581-1594.

5. Parsons KC (1993) Human Thermal Environments, the effects of hot, moderate and cold environments on human health, comfort and performance: the principles and the practice. Taylor and Francis, London.

6. Ho C, Fan J, Newton E, Au R (2008) Effects of athletic T-shirt designs on thermal comfort. Fibers and Polymers 9: 503-508.

7. Ruckman J, Hayes S, Cho J (2001) Development of a perfusion suit incorporating auxiliary heating and cooling system. Int J Clothing Science and Technology 14: 11-24.

8. Zhang X, Li J, Wang Y (2012) Effects of clothing ventilation openings on thermoregulatory responses during exercise. Indian J Fibre and Textile Research 37: 162-171.
9. Qian X, Fan J (2006) Prediction of clothing thermal insulation and moisture vapor resistance of the clothed body walking in wind. Annals of Occupational Hygiene 50: 833-842.

10. Bouskill LM, Havenith G, Kuklane K, Parsons KC, Withey WR (2002) Relationship between clothing ventilation and thermal insulation. AlHA J 63: 262-268.

11. Havenith G, Heus R, Lotens WA (1990) Resultant clothing insulation: a function of body movement, posture, wind, clothing fit and ensemble thickness. Ergonomics 33: 67-84

12. Nielsen R, Olesen BW, Fanger PO (1985) Effect of physical activity and air velocity on the thermal insulation of clothing. Ergonomics 28: 1617-1631.

13. Vokac Z, Kopke V, Keul P (1973) Assessment and Analysis of the Bellows Ventilation of Clothing. Textile Research J 43: 475-482.

14. Olesen BW, Sliwinska E, Madsen TL, Fanger PO (1982) Effect of body posture and activity on the insulation of clothing: measurement by a movable thermal manikin. ASHARE Transactions 88: 791-805.

15. Peteu MC, Helvenston Gray S (2009) Clothing invention: Improving the functionality of women's skirts, 1846-1920. Clothing and Textiles Research J 27: $46-61$.

16. Farrell-Beck J, Poresky L, Paff J, Moon C (1998) Brassieres and women's health from 1863-1940. Clothing and Textiles Research J 16: 105-115.

17. Helvenston, Gray S, Peteu MC (2005) Invention, the angel of the nineteenth century: Patents for women's cycling attire in the 1890s. Dress 32: 27-42.

18. Zelano J (1944) Ventilated clothing, US Patent US2391535A

19. Bengtsson AG, Mullsjo KE (1980) Garment for use in vigorous physical activities. US Patent 4195364.

20. Gioello DA (1984) Ribbed ventilating undergarment for protective garments. US Patent 4451934

21. Lemonine PG (1991) Ventilated beekeeper suit. US Patent US4985933

22. Crown E, Ackerman MY, Dale JD, Tan Y (1998) Design and evaluation of thermal protective flight suits. Part II: Instrumented mannequin evaluation. Clothing and Textile Research Journal 16: 79-87.

23. Dlugosch S, Hu H, Chan A (2013) Thermal comfort evaluation of equestrian body protectors using a sweating manikin. Clothing and Textile Research $\mathrm{J}$ 31: $231-243$.

24. Fan J, Chen YS (2002) Measurement of clothing thermal insulation and moisture vapor resistance using a novel perspiring fabric thermal manikin. Measurement Science and Technology 13: 1115-1123. 